\title{
Experiment Research on the Mechanical Performance of EPDM Insulation Pyrolysis Process
}

\author{
Jing Jiang, Jin-sheng $\mathrm{Xu}$, Xiong Chen \& Zhong-shui Zhang \\ Department of Institute of Mechanical Engineering, Nanjing University of Science and Technology, \\ Nanjing, 210094, China
}

Keywords: Ethylene Propylene Diene Monomer (EPDM); Thermogravimetric Analysis (TGA); SHPB; High rate; Stress-strain curves

\begin{abstract}
In order to study the pyrolysis process of Ethylene Propylene Diene Monomer (EPDM) insulation material and its compression mechanical behaviour under high strain rates, the thermal stability of EPDM was analysed by TGA in the first place. Based on the TG curve and the thermal degradation temperature, the resistance furnace was set at different temperature to complete the heat preservation experiment. Then dynamic compression tests were conducted by using the split Hopkinson pressure bar. The stress-strain curves of EPDM material were obtained by processing the experimental signals under high strain rates. The results showed that the material became porous layers gradually with the increase of heat preservation temperature. Pyrolysis gas resulted in the bulge, even beat burst on the surface of tested samples. In the initial stage of pyrolysis, the compressive strength of the material increased with the temperature rise. Moreover, under the same conditions of the strain rate and strain, the stress increased with the temperature rise. When the temperature reached to $300{ }^{\circ} \mathrm{C}$, the mechanical properties of EPDM mutated. By electron spectroscopy (EDS) analysis, it was considered that the neoprene pyrolysis led to the change of the material performance of EPDM.
\end{abstract}

\section{Introduction}

EPDM (Ethylene Propylene Diene Monomer) is a terpolymer, consisting of ethylene, propylene and non-conjugated diene, and is widely used in the aerospace field, such as an ideal insulation material for solid rocket motor, for its outstanding performance of low density, high thermal-decomposition temperature, large specific heat, extraordinary aging resistance and so on. As the thermal protective layer of the combustion chamber, EPDM plays a key role of preventing the shell of the combustion chamber from the high internal temperature, high-speed gas flow and particulate erosion. Currently EPDM insulation has been applied throughout different types of solid rocket motors.

With the increase of the pressure in the chamber, and the application of high burning rate propellant and high energy propellant [1-3], all the performance requirements of EPDM insulation should be improved. In recent works, many researchers focused on the formula of insulation material and its ablation mechanism. Maurizio[4] compared the mechanical properties and excellent thermal stability of EPDM based heat shielding materials for solid rocket motors with different fibrous reinforcements. Vojislav[5] investigated the effect of carbon black filler (CB) on the cure kinetics, mechanical properties, morphology and thermal stability of acrylonitrile-butadiene/ethylene-propylene-diene (NBR/ EPDM) rubber blends. Yunyun Jiang[6] discovered that PPSQ microspheres served as an effective ablative additive and flame retardant for EPDM composites, greatly improved the ablative properties. Liu Yang[7] studied the ablation mechanism and model of EPDM insulator under high acceleration condition. However, in current work, this paper mainly concentrated on the pyrolysis process of EPDM material. As the insulation material applied in the solid rocket motor, EPDM material will become porous when it pyrolyzed completely or stepped into the stage of carbonization, then it would be vulnerably washed away by the high-speed gas and particles. Thus, this research was centered on the mechanical properties of EPDM at the beginning of the pyrolysis.

Heat preservation experiments of EPDM insulation under different temperature have been 
completed based on the results of Thermogravimetric Analysis (TGA). In addition, dynamic compression experiments have been carried out by using SHPB apparatus in order to reveal the mechanical characteristics of EPDM material under high strain rate at different degrees of pyrolysis. It will provide valuable theoretical basis for the thermal insulation structure design inside of a rocket motor and the establishment of the ablation model of EPDM material.

\section{Thermal pyrolysis experiment}

The raw material for these experiments was a disc-shaped EPDM insulation, which was widely used at the end of the propellant in the solid rocket motor. To investigate the pyrolysis characteristics of the EPDM material, the process of pyrolysis was explored by thermogravimetric analysis. The specimens were prepared through the heat preservation experiment for further study on the mechanical properties of EPDM material at different degrees of pyrolysis.

\section{TG analysis}

Thermogravimetric analyzer is mainly suitable for the phenomenon such as the material transformation, decomposition, combination, dehydration, parsing, sublimation, evaporation, as well as identification analysis of the material, component analysis and the measurement of thermal parameters and dynamics parameter, etc. Thermogravimetric analysis (TGA) was performed over the temperature range $50-800^{\circ} \mathrm{C}$ on a thermal analyzer at a heating rate of $60 \mathrm{C} / \mathrm{min}$ under a nitrogen atmosphere. Small pieces of the original samples were placed on a crucible. The experiments were recorded under linear heating, isothermal and controlled rate thermal analysis in nitrogen. The TG curve of EPDM insulation obtained was used to investigate the material thermal stability, as shown in Fig. 1.

The initial weight of the sample was $6.56 \mathrm{mg}$, after the pyrolysis process, the final sample was $3.18 \mathrm{mg}$ with $51.54 \%$ mass reduction. From Fig. 1, it illustrates 3 significant inflection points on the TG curve. When the specimen was heated to $170{ }^{\circ} \mathrm{C}$, the quality of the specimen began to declinegradually .when temperature exceeded $270{ }^{\circ} \mathrm{C}$, the quality decreased rapidly until the decrease speed began to slow down at the temperature of $380{ }^{\circ} \mathrm{C}$, but gradually recovered to previous decrease speed. when the temperature reached $530{ }^{\circ} \mathrm{C}$, the quality of the remaining sample tended to be a constant value. The TG curve of EPDM material laid the foundation for the experiment research of material pyrolysis.

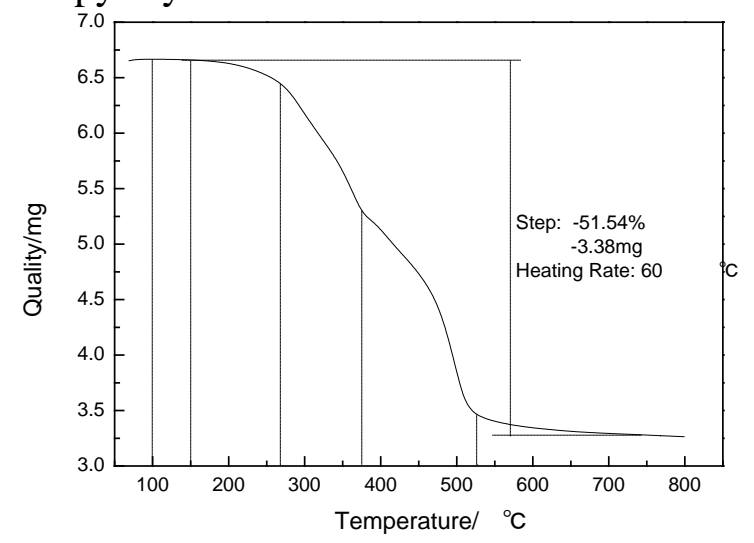

Fig. 1 TG curve of EPDM

\section{Heat preservation experiment}

The original EPDM insulation material was processed into cylindrical specimens through mechanical processing method. The material mainly contains $\mathrm{C}, \mathrm{O}, \mathrm{Zn}, \mathrm{Mg}, \mathrm{Al}, \mathrm{Si}, \mathrm{P}, \mathrm{S}, \mathrm{Cl}$ and other elements, of which the element contents are 46.54\%, 26.91\%, 1.29\%, 0.40\%, 11.45\%, 4.48\%, $0.65 \%, 0.18 \%$ and $6.58 \%$, respectively. The specimen dimensions were $6 \mathrm{~mm}$ in thick and $8 \mathrm{~mm}$ in diameter in order to fit the requirement during the dynamic compression tests. After that, these specimens were kept for a week to recovery the machining residual stress.

The specimens were heated in SRJX8-13 box-type resistance furnace. Based on the TG curve of 
EPDM material, the temperatures in the resistance box were set at $100{ }^{\circ} \mathrm{C}, 150{ }^{\circ} \mathrm{C}, 200{ }^{\circ} \mathrm{C}, 250{ }^{\circ} \mathrm{C}$, $300{ }^{\circ} \mathrm{C}, 350{ }^{\circ} \mathrm{C}$ and $550{ }^{\circ} \mathrm{C}$, respectively. Each specimens were kept for two hours.

After the heat preservation experiments, the specimens got cool in room temperature. It can be discovered that the surface and interior of the specimen was grass green at $100^{\circ} \mathrm{C}$ and $150{ }^{\circ} \mathrm{C}$, as shown in Fig. 2. When the heat preservation temperature was $200{ }^{\circ} \mathrm{C}$, the specimen surface was brown but its interior was green. The specimen surface was dark brown and its interior was brown at $250{ }^{\circ} \mathrm{C}$. When reached $300{ }^{\circ} \mathrm{C}$ and above, the surface was black and plump with the pyrolysis gas. The bulge ruptured with the raising temperature. The profile was like porous layers, as shown in the top right corner of Fig. 2. After the specimens became cooling, two end face of the cylindrical specimens were burnished by the sand paper to ensure its parallelism and smoothness.

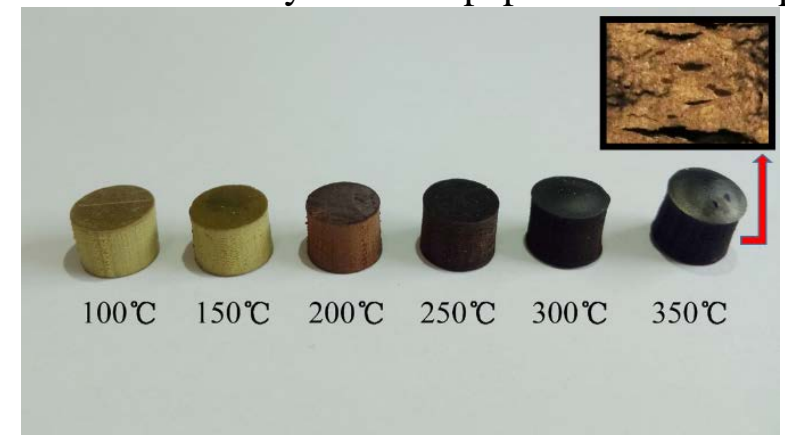

Fig. 2 Topography of EPDM at different temperatures

\section{High strain rate experiment and analysis}

The compression mechanical properties of EPDM material through heat preservation experiments under high strain rates were investigated by SHPB . The changes of the mechanical behaviour of EPDM and its reasons are analyzed.

\section{SHPB experiment}

Our dynamic compression experiments were performed by the SHPB apparatus which consists of an air gun, a striker, incident bar, transmission bar, velocity measuring device and data acquisition equipment. The pressure bars were made of LC4 ultra-high-strength aluminum alloy (superhard aluminium) with Young's modulus of $70 \mathrm{GPa}$ and density of $2.66 \times 103 \mathrm{~kg} / \mathrm{m} 3$. Both the incident bar and transmission bar were $14 \mathrm{~mm}$ in diameter, and $1400 \mathrm{~mm}$ in length. The length of the striker was $400 \mathrm{~mm}$. A thin layer of lubricant oil was coated on the contacting surfaces of the specimen in order to decrease the influence of interface friction.

These experiments were carried out at room temperature. The air gun pressure was set at 0.15 $\mathrm{MPa}$. During the high strain rate tests, the specimens which heat preservation temperature above $350{ }^{\circ} \mathrm{C}$ were impacted into powder after dynamic loading. The strain gauge attached on the transmission bar was unable to collect the transmission signal. When EPDM material was applied in solid rocket motors, high speed gas and particles produced by the propellant grain burning would take away the porous and loose material after EPDM pyrolyzing completely or stepping into the stage of carbonization. Thus, this paper mainly studies the mechanical properties of EPDM insulation in the early pyrolysis step, which means the heat preservation temperature is between $100{ }^{\circ} \mathrm{C}$ to $300{ }^{\circ} \mathrm{C}$. Four specimens of each group were tested. And the average curves were taken as the research objects.

\section{Experimental data processing}

Two-wave method and Matlab programme were used to deal with the recorded signals through the dynamic compression experiments of original material and specimens heated from $100{ }^{\circ} \mathrm{C}$ to $300{ }^{\circ} \mathrm{C}$. Verify that the specimens were in uniform stress and loading at constant strain rate during the experiments to ensure the validity of the experiment results. The material stress-strain and strain rate-strain curves were obtained.

Fig. 3 shows four repeated experiment curves of the specimens heated at $250{ }^{\circ} \mathrm{C}$ for 2 hours. 
The stress first rose fast in linear and then rose slightly. The curves showed a good agreement. The average curve was taken as the representative mechanical behavior of EPDM material at $250{ }^{\circ} \mathrm{C}$. The average strain rate-strain curves of the original material and others heated at different temperatures were shown in Fig. 4. Therefore, it can be considered that all the curves of EPDM insulation in diferent conditions represent mechanical properties at the strain rate of $1750 \mathrm{~s}-1$, as shown in Fig. 5. From Fig. 5, it can be discovered that the stress increases with the increase of the temperature, which means that the deepening of the pyrolysis of EPDM enhances the material compressive strength. The mechanical behaviors of the original material and specimens heated from $100{ }^{\circ} \mathrm{C}$ to $250{ }^{\circ} \mathrm{C}$ exhibited the same trend. It can be roughly divided into three stages: linear increase stage, slow growth stage and stress unloading stage. When the temperature reached $300{ }^{\circ} \mathrm{C}$, obviously, the stress-strain curve showed a different trend, which meant that the mechanical properties of EPDM material had changed a lot.

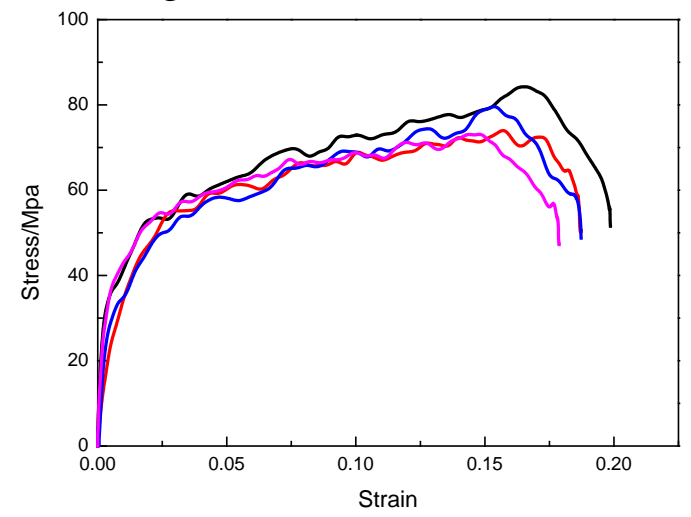

Fig. 3 Repeated experimental results at $250^{\circ} \mathrm{C}$

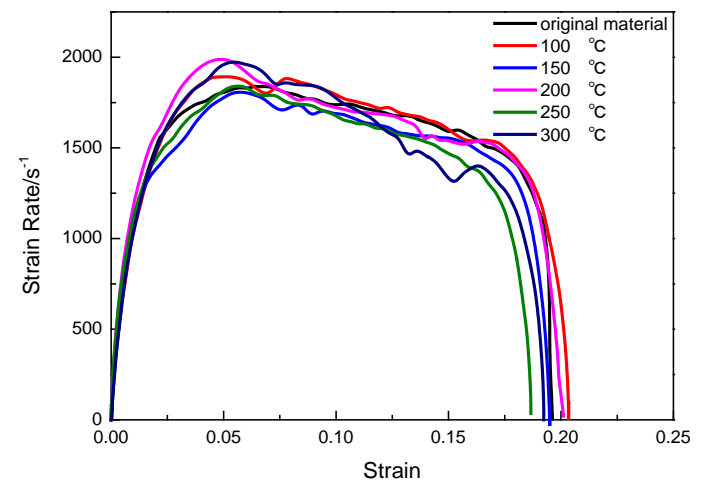

Fig. 4 Strain rate-strain curves

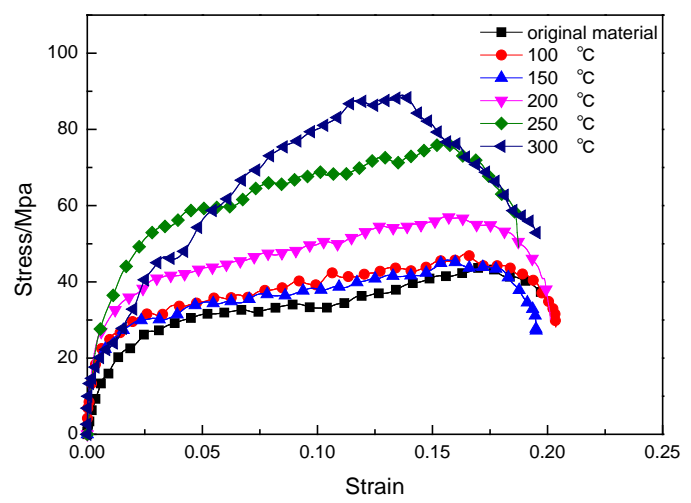

Fig. 5 Stress-strain curves of EPDM under different temperatures

\section{Experiment results analysis}

From the stress-strain curves, we can find that mechanical properties of EPDM material which heated at $100{ }^{\circ} \mathrm{C}$ and $150{ }^{\circ} \mathrm{C}$ are almost the same. And then the stress at same strain increase with the temperature rise. From the TG curve obtained before, the weight of EPDM sample did not 
decrease until the temperature was over $170{ }^{\circ} \mathrm{C}$. Hence, the material didn't change, their mechanical behaviors were similar. The material began to pyrolyze with the rise of the temperature. The gap of the stress-strain curves was very large under the same temperature difference. This phenomenon is consistent with the researches of Lou Cheng-yu[8] and Lu Qin-fang[9]. The side group oxidation reactions of rubber material occurred in the condition of oxygen and high temperature, resulting in the cross-linking hardening. Till $300{ }^{\circ} \mathrm{C}$, the material performance changed, the elastic soft material changed into porous brittle material. It was discovered that chlorine had obvious changes in the material through electron spectroscopy (EDS) analysis. The element content of chlorine declined from $6.58 \%$ to 3.49\%, as shown in Table 1. He-ping Yu[10] and Xing-kun Yang [11] found that the sharply thermal degradation temperature of neoprene was about $260 \sim 390{ }^{\circ} \mathrm{C}$. Thus, it is considered that the pyrolysis of neoprene causes the change of mechanical properties of EPDM insulation.

Table 1 Elements contained original material and $350{ }^{\circ} \mathrm{C}$ heat preservation material

\begin{tabular}{cccccccccc}
\hline element & $\mathrm{C}$ & $\mathrm{O}$ & $\mathrm{Mg}$ & $\mathrm{Al}$ & $\mathrm{Si}$ & $\mathrm{P}$ & $\mathrm{S}$ & $\mathrm{Cl}$ & $\mathrm{Zn}$ \\
\hline original & $46.54 \%$ & $26.91 \%$ & $0.40 \%$ & $11.45 \%$ & $4.48 \%$ & $0.65 \%$ & $0.18 \%$ & $6.58 \%$ & $1.29 \%$ \\
$350^{\circ} \mathrm{C}$ & $47.12 \%$ & $29.28 \%$ & $0.43 \%$ & $11.21 \%$ & $5.39 \%$ & $1.23 \%$ & $0.22 \%$ & $3.49 \%$ & $1.56 \%$ \\
\hline
\end{tabular}

\section{Conclusion}

The mechanical properties of EPDM insulation and its pyrolysis process are obtained through thermogravimetric analysis, heat preservation experiments and dynamic compression tests. The following conclusions can be acquired:

The thermal degradation process of EPDM material is divided into two phases: $200 \sim 370{ }^{\circ} \mathrm{C}$ and $370 \sim 530{ }^{\circ} \mathrm{C}$, the material mass is reduced about 51\% in total. The bulges appeared on the specimens surface which were caused by the gas produced during the pyrolysis. The specimens gradually changed from the original dense into loose layers with the rising temperature.

The stress increases with the rise of the temperature. The stress-strain curves can be roughly divided into three stages: linear increase stage, slow growth stage and stress unloading stage when the heat preservation temperature was below $250{ }^{\circ} \mathrm{C}$. The deepening of the pyrolysis of EPDM enhances the material compressive strength. In the condition of oxygen and high temperature, side group oxidation reactions of rubber material occurred which resulted in the cross-linking hardening.

The mechanical response of EPDM material mutated at $300{ }^{\circ} \mathrm{C}$.According to the EDS analysis, it is considered that the mass degradation of neoprene at $260 \sim 390{ }^{\circ} \mathrm{C}$ causes the change of mechanical properties of EPDM insulation.

\section{Acknowledgements}

This work was sponsored by the department of Aeronautics and Astronautics of China. Prefessor Xiong Chen is the corresponding author. The authors would like to thank Dr S.Q. Hu for proof reading the paper, and $\mathrm{Mr} \mathrm{X}$. Tong and $\mathrm{Mr}$ S.E Ma for ongoing technical support. The authors are grateful to Mr R.M. Ran for his help using the camera.

\section{References}

[1] Dubey R, Chawla M, Siril P F, et al. Bi-metallic nanocomposites of Mn with very high catalytic activity for burning rate enhancement of composite solid propellants[J]. Thermochimica Acta, 2013, 572: 30-38.

[2] Guo X D, Li F S, Song H C, et al. Catalytic combustion properties of a new high burning rate propellant [J]. Journal of Propulsion Technology, 2007, 28(2): 220-224.

[3] Kokan T S, Olds J R, Seitzman J M, et al. Characterizing high-energy-density propellants for space propulsion applications[J]. Acta Astronautica, 2009, 65(7): 967-986. 
[4] Natali M, Rallini M, Puglia D, et al. EPDM based heat shielding materials for Solid Rocket Motors: A comparative study of different fibrous reinforcements[J]. Polymer Degradation and Stability, 2013, 98(11): 2131-2139..

[5] Jovanović V, Samaržija-Jovanović S, Budinski-Simendić J, et al. Composites based on carbon black reinforced NBR/EPDM rubber blends[J]. Composites Part B: Engineering, 2013, 45(1): 333-340.

[6] Jiang Y, Zhang X, He J, et al. Effect of polyphenylsilsesquioxane on the ablative and flame-retardation properties of ethylene propylene diene monomer (EPDM) composite[J]. Polymer Degradation and Stability, 2011, 96(5): 949-954.

[7] Liu Y, Li J, He G Q, et al. Experiment on ablation characteristic of EPDM insulator under particles erosion condition[J]. Journal of Propulsion Technology, 2010, 31(5): 612-617.

[8] Lou C Y. The synthesis and processing technology of ethylene propylene rubber [M]. Beijing: Chemical Industry Press, 1982.

[9] Lu Q F, Xu C L, Li X B, et al. Study on experimental preparation and thermal properties of heat-resistant silicone rubber[J]. Experimental Technology and Management, 2013, 30(9): 50-52.

[10] $\mathrm{Yu} \mathrm{H,} \mathrm{Li} \mathrm{S,} \mathrm{Zhong} \mathrm{J,} \mathrm{et} \mathrm{al.} \mathrm{Studies} \mathrm{of} \mathrm{thermooxidative} \mathrm{degradation} \mathrm{process} \mathrm{of} \mathrm{chlorinated}$ natural rubber from latex[J]. Thermochimica Acta, 2004, 410(1): 119-124.

[11] Yang X K, Hu F X. Thermal degradation kinetics of chloroprene rubber grafting butyl methacrylate[J]. China synthetic Rubber Industry, 2008, 30(5): 343-347. 